\title{
Castigos, fugas y resistencias femeninas en el Río de la Plata colonial. Mujeres indígenas y españolas en historias conectadas
}

Punishments, leaks and feminine resistances in the colonial Rio de la Plata. Spanish and indigenous women in connected stories

Lia Quarleri

Universidad Nacional de San Martín. Instituto de Altos Estudios Sociales - CONICET, Argentina

liaquarleri@yahoo.com.ar

\section{Resumen:}

En el presente trabajo se analizarán las implicancias del castigo corporal, en la forma de azotes y reclusión femenina, para mostrar cómo mujeres indígenas y mujeres españolas se encontraron, comúnmente, afectadas por políticas disciplinares del cuerpo. Se parte de dos casos judiciales suscitados, a fines del siglo XVIII, en las reducciones guaraníes pos-jesuitas y en la ciudad de Buenos Aires. La metodología utilizada es el análisis de fuentes históricas desde la perspectiva de género y los estudios interdisciplinarios del cuerpo. La conclusión es que los castigos físicos condensaron concepciones específicas sobre el cuerpo femenino, políticas de dominio colonial y tradiciones jurídicas que respaldaron sistemas patriarcales que atravesaron contextos políticos y marcos culturales.

Palabras Clave: Castigos Corporales, Encierros, Fugas, Mujeres, Misiones Guaraníes, Argentina.

\section{AbstraCt:}

This paper analyses the implications of corporal punishment to show how indigenous and Spanish women have been affected by disciplinary corporeal polices. The work focuses on two court cases that had arisen at the end of the 18th century in the postJesuit Guarani reductions and in the city of Buenos Aires. The methodology used is the analysis of historical sources from the perspective of gender and the interdisciplinary studies of the body. The conclusion is that corporal punishment condensed specific conceptions of the female body, policies of colonial domination and legal traditions that legitimized patriarchal systems, that went through political contexts and cultural frameworks.

KEYWORDs: Corporal Punishments, Prison, Women, Guaraní Missions, Argentina.

\section{INTRODUCCIÓN}

El sistema colonial americano consolidó y legó una historia de marcaciones y clasificaciones corporales sobre las que se erigieron desigualdades sociales, etno-raciales y de género. ${ }^{1} \mathrm{El}$ poder racializado como el poder de género atravesaron todas las esferas y dimensiones de la vida política, jurídica y socio-económica, a lo largo de las extensas y heterogéneas regiones que componían los dominios hispanoamericanos. En términos específicos, las relaciones y estructuras de género conjugaron tradiciones culturales prehispánicas, circunstancias locales y procesos de occidentalización. El poder de género, con sus diversidades contextuales, se expresó en la configuración de deberes y derechos desiguales que conformaron pactos implícitos al sistema patriarcal colonial, cuya evasión o trasgresión fue penada por los garantes del mismo. Imputaciones sociales, castigos físicos domésticos y penas corporales, dictaminadas o avaladas por la justicia, las élites sociales y el poder político se desplegaron a los fines de modelar y direccionar los vínculos y las jerarquías sociales. Los castigos del cuerpo, a su vez, condensaron políticas de control poblacional, asociadas a sistemas de gobierno y matrices religiosas, moralidades y códigos de honor determinados. 
En el presente trabajo se analizarán las implicancias del castigo corporal, en la forma de azotes y reclusión femenina, a partir del estudio de dos casos judiciales suscitados a fines del siglo XVIII en las reducciones guaraníes pos-jesuitas y en la ciudad de Buenos Aires. Con ello, se busca dar cuenta acerca de cómo los castigos, respaldados sobre determinadas concepciones del cuerpo, fueron la respuesta institucionalizada a resistencias femeninas que se expresaron, en estos casos, en denuncias judiciales de maltrato y en ausencias e incumplimientos de los deberes asignados a las mujeres de acuerdo a su lugar en la sociedad. Finalmente, interesa mostrar cómo mujeres indígenas de pueblos de reducción y mujeres españolas de capitales virreinales se encontraron atravesadas por políticas compartidas de disciplinamiento, como eran los encierros en casas de recogidas. ${ }^{2}$ Los castigos físicos aplicados sobre mujeres guaraníes fueron analizados, previamente, en tanto expresión de disputas políticas, coacción económica y medios correctivos, en el contexto reduccional jesuita y pos-jesuita (Quarleri, 2018). La dimensión punitiva recaída sobre los cuerpos femeninos, estudiada precedentemente para otras regiones coloniales por investigadoras como Alejandra Araya Espinosa (2004, 2006 y 2014), despertó el interés por conectar historias de mujeres que bajo situaciones jurídicas y sociales diferentes fueron castigadas o encerradas por evadir normas implícitas al poder colonial patriarcal. Los casos seleccionados forman parte de un reservorio más amplio. ${ }^{3}$ La selección respondió al objetivo de comparar analíticamente las experiencias de mujeres indígenas y españolas, en un mismo período y espacio regional, castigadas por incurrir en los delitos de evasión, insubordinación y fuga.

La criminalización de las fugas se inscribió dentro de una tradición colonial de control poblacional y de reducción de sujetos a espacios determinados. Por su parte, el derecho penal colonial se configuró dentro de una sociedad étnica y jurídicamente estratificada, la cual estaba sustentada, a su vez, sobre la potestad de imponer castigos distintos para los hispanos, los indígenas y los esclavos de origen africano. Las penas corporales constituyeron uno de los principales castigos dentro del sistema penal de la monarquía católica, configurados a los fines de amedrentar como medio de gobierno (Tomás y Valiente, 1969). ${ }^{4} \mathrm{Al}$ respecto, una renovada historiografía sobre los estudios del cuerpo y las clasificaciones sociales indagó en la estipulación de los delitos y en la aplicación de las penas según la condición jurídica, el grupo social de pertenencia y las condiciones de vida (Albornoz Vásquez y Argouse, 2009 y Vassallo, 2006). Las perspectivas metodológicas interdisciplinarias, plasmadas por exponentes como Farge (2008); Le Goff y Truong (2005) y Vigarello (2005a), constituyen marcos estructurales del presente trabajo. La relación entre cuerpo, gobierno e ideología es tributaria de un campo epistemológico de reflexión filosófica e histórica que tiene a la figura de Michel Foucault como uno de sus principales exponentes. Finalmente, la preocupación por las relaciones entre poder de género, normas sociales, conceptos de pureza y castigos del cuerpo, tratados desde la perspectiva antropológica por Mary Douglas (1973) en su clásico trabajo "Pureza y peligro", conforma también un referente fundamental del presente trabajo.

Los cuerpos situados, histórica y culturalmente, entendidos como signos, concentraron siempre densos entramos de significaciones. Semióticas complejas del cuerpo legitimaron, a su vez, usos, castigos y manipulaciones políticas de las marcaciones sociales, así como su inscripción dentro de determinadas relaciones y configuraciones de poder. Se parte de la idea de que los castigos corporales condensaron, en el contexto estudiado, no solo dominios, pedagogías y penalidades diferenciales, sustentadas sobre marcas de origen, género y condición social, sino también un campo de disputas entre actores rivales. Específicamente, competencias entre poderes masculinos por el control de los cuerpos femeninos, despersonalizados y subalternizados. Asimismo, los castigos físicos y encierros en casas de recogidas buscaron marcar e inmovilizar los cuerpos de aquellas mujeres que con sus fugas y evasiones a las normas y obligaciones de género expresaron resistencias y atentaron contra la hegemonía normativa del poder patriarcal colonial. Las concepciones religiosas en torno a las prácticas purificadoras del cuerpo, trasmitidas en tratados, en el púlpito o durante la confesión, alimentaron esos sistemas de control social del cuerpo femenino.

Hacia fines del siglo XVIII, se expresaron nuevas políticas de gobierno y concepciones sobre la administración de la población colonial, dentro de un marco más amplio de reformas fiscales, socio-jurídicas, 
correctivas e higienistas. Los tribunales civiles constituyeron una de las esferas institucionales en las que se registraron ciertos cambios. En Buenos Aires, si bien los tribunales propugnaron castigos de género también permitieron, por la propia existencia de regulaciones en torno a lo legítimo y lo abusivo, la canalización de denuncias de abuso, maltrato e incumplimiento de pactos matrimoniales. A partir de la década de 1780, comenzó a notarse la influencia de las "corrientes propiciatorias de la libertad social de la Ilustración”, en las decisiones tomadas en el terreno del derecho de familia (Kluger, 2003, p. 4). En esa línea, la administración secular instalada en las reducciones guaraníes, tras la expulsión de los jesuitas, fomentó la realización de denuncias contra los abusos de poder, lo que fue utilizado políticamente en la lucha de intereses (Quarleri, 2018). En todos los casos, la disposición de redes familiares o políticas y los recursos económicos conformaron herramientas fundamentales para litigar en los tribunales. En ese sentido, las españolas de la elite o las españolas pobres y las indígenas, mestizas, mulatas o esclavas no se encontraron, frente a esas instancias, en la misma situación. Al respecto, según Mallo (1990), las mujeres españolas de los sectores bajos se movieron con mayor "libertad sexual" pero también padecieron, con mayor recurrencia, actos de criminalización judicial. En las siguientes páginas, se presentarán y contextualizarán dos casos judiciales que pusieron en escena los alcances, los límites y los objetivos de los castigos corporales, impartidos de forma trasversal a mujeres indígenas y mujeres españolas, en una macro región interconectada.

\section{María Irapayu y María Rafaela ante la Justicia y el PODER Patriarcal colonial}

La creación de las Reales Audiencias americanas y la potestad dada a ciertas autoridades locales, tales como gobernadores, cabildos y virreyes, para dirimir litigios conformaron diferentes instancias de alegación, defensa y resistencia que utilizaron, en diferente grado, sujetos particulares o colectivos sociales. La restitución de la Real Audiencia de Buenos Aires, en 1785, tras una breve existencia en el siglo XVII, movilizó la presentación de demandas ante ese Tribunal, por parte de diferentes sectores de la población rioplatense. Sin embargo, existieron denuncias, para la región analizada, sobre abusos y violencias realizadas por mujeres, a lo largo de todo el período colonial. Al respecto, mujeres de condiciones socio-jurídicas distintas accedieron a diferentes instancias judiciales, dentro de marcos de amparo social, económico o político. Cuando decidían involucrarse o quedaban involucradas en un proceso judicial, otros sujetos, familiares o allegados aparecían en los expedientes de forma explícita o subliminar apoyando sus acciones. Esto podía observarse a través de las declaraciones de los testigos presentados en los juicios. Asimismo, el contexto y las condiciones en las que se encontraban influyeron, en términos generales, en la decisión de denunciar. En ese sentido, una mujer española que residía en la capital virreinal, aunque no formara parte de la élite porteña, contaba con mayores elementos para hacer una acusación porque su condición de libertad jurídica era otra y porque la disposición de recursos, información, contactos y cercanía física, a los distintos tribunales o autoridades competentes, lo hacían posible.

En contraposición, una mujer guaraní que habitaba en una de las treinta reducciones antiguamente fundadas por los jesuitas se encontraba en la práctica bajo una condición servil que limitaba en extremo sus posibilidades de manifestar, sin intermediaciones, los maltratos vividos. Las mujeres de los pueblos estuvieron sujetas, situacionalmente, a la jurisdicción superpuesta y jerárquica de varias autoridades (jesuitas, caciques, corregidores y maridos) en tiempos de los ignacianos, a los que se sumó una nueva capa de administradores, tras la expulsión. Los matrimonios cristianos, impuestos tempranamente por los jesuitas, configuraron nuevos tipos de vínculos que conllevaron la imposición de lógicas distintas. Esto implicó, en la práctica, adaptaciones que involucraron disquisiciones morales y políticas al interior de la orden (Imolesi, 2017). Con las reformas borbónicas y la expulsión de los jesuitas, se instaló en las reducciones guaraníes una administración hispana, con ansias de abrir las mismas al comercio colonial, que pasó a disputar el poder de las autoridades indígenas existentes y a crear redes cruzadas con algunas de ellas. En consecuencia, el modelo político configurado por los ignacianos de carácter cerrado, jerárquico y centralizado se resquebrajó. Antiguos 
y flamantes actores políticos entraron en pugna por el control del poder, la fuerza de trabajo indígena y los codiciados recursos misioneros. La fragmentación y la competencia fomentaron la realización de denuncias de viejos y nuevos abusos, en los que los padecimientos de las mujeres, por las condiciones de vida y los castigos pergeñados, sobresalieron drásticamente. El comercio aceleró, a su vez, la presión laboral ejercida sobre ellas. En particular, sobre las obligaciones de hilado de algodón, exigidas en mayor cantidad (Quarleri, 2018 y Sarreal, 2014).

A partir de la creación del Virreinato del Río de la Plata, en 1776, y la aplicación del Reglamento de libre comercio, en 1778, la región misionera quedó unida a Buenos Aires, capital virreinal. Al mismo tiempo, una intensa dinámica mercantil y poblacional tuvo a ambos lugares como polos de atracción. La ciudad, su puerto y su área de influencia manifestaron un enorme crecimiento político y económico que fomentó la radicación de numerosos españoles, portugueses y migrantes internos (Johnson, Socolow y Seibert, 1980). Por su parte, en las antiguas fronteras del Plata, donde se localizaban los pueblos guaraníes, el estado colonial emprendió, a través de funcionarios y particulares, una colonización de tierras misioneras y recursos productivos que conllevó una dilapidación de los cultivos de algodón, yerbales silvestres y ganado vacuno. Se impuso, además, la asimilación de la población indígena bajo una política de erradicación de costumbres, idioma y formas de vida locales (Caletti Garciadiego, 2015; Maeder, 1992; Moraes, 2007; Quarleri, 2012 y Ratto, 2015). Los casos judiciales se insertan en el contexto descripto.

El primer caso está situado en los pueblos guaraníes pos-jesuíticos. El litigio a analizar se originó, en enero de 1788, cuando un cacique guaraní del pueblo de San Lorenzo denunció ante las autoridades hispanas del complejo misionero que María Irapayu, su mujer, había sido azotada por faltar a la cosecha comunal de trigo. ${ }^{5}$ Por un lado, se argumentó que el corregidor Miguel Guiraobi había ordenado castigarla con azotes como con tarea diaria, sin contemplar las diversas obligaciones que recaían sobre ella. Al respecto, María declaró que, ese mismo día, había sido “enviada (por su marido) a la chacra a recoger choclos para su manutención” (Provisión, 1788 , f. 1). De esta forma, demandada y exigida por tareas laborales de la administración colonial, por las actividades comunes al pueblo y por las actividades domésticas, María a través de su marido hizo su descargo para justificar su ausencia. El teniente de gobernador del departamento de San Miguel, el español Manuel de Lasarte y Esquivel, dio curso legal a la denuncia con presentación de testigos, tras lo cual se dio a conocer que otras mujeres también habían sido azotadas por no concurrir a la cosecha. El teniente de gobernador actuó en este caso como receptor de la denuncia, en representación del gobernador de Misiones, ya que no implicaba un delito mayor. El gobernador de Misiones, por su parte, respondía a los gobernadores de Paraguay y Buenos Aires, a los intendentes o al virrey, según la época y las circunstancias. En la práctica, las competencias y conflictos de poder fueron la norma. Por otro lado, los corregidores de origen guaraní, hispanizados, tenían, desde los tiempos jesuíticos, la potestad de corregir y castigar a la población para imponer las obligaciones laborales. Sin embargo, su rol derivó en amplios abusos de autoridad.

Luego de los testimonios, se exhortó al corregidor Guiraobi a que "conteste legalmente" a cada una de las imputaciones. En su declaración, el corregidor defendió sus acciones y aseveró que como "en la faena de la siega de trigo" del pueblo se necesitaban muchas personas y por "ser este pueblo de muy poca gente" mandó "que fueran a recoger las espigas a dichas faenas" a "las mujeres, muchachos y muchachas como sucede en todos los demás pueblos" (Declaración, 1788, f.1). Para contar con la “ayuda” de las mujeres del pueblo argumentó haberlas exonerado de la tarea de hilado y que

habiendo faltado varias mujeres a la expresada faena que ni daban tarea ni asistían al trabajo y llamándolas u preguntándoles el cabildo porque faltaban al trabajo de comunidad siendo así que eran hijas del pueblo y se les daba de comer, vestir y demás que necesitaban como a todos los demás y habiendo una de ellas, María Irapayu, mujer de Agustín Guaraye lo que contestando con desvergüenzas y replicas al cabildo mandaron para contenerla dar seis azotes por otra de su clase por encima de la ropa en las nalgas y que después diera por un día tarea de hilado (Declaración, 1788, f. 2).

La averiguación judicial dio a conocer las disputas entre caciques, corregidores y administradores hispanos por el control de los cuerpos productivos de las mujeres. En esa línea, el litigio plasmó el reclamo del cacique de 
San Lorenzo, Agustín Guairaye, no solo por el castigo abusivo dado a María Irapayu por parte del corregidor indígena, con el que estaba enemistado, sino porque las nuevas demandas comunales le quitaban tiempo, a su mujer, para recolectar maíz para su unidad doméstica. En el caso de las mujeres guaraníes, a las antiguas demandas solicitadas en los tiempos jesuíticos, como era el trabajo en los campos, el trabajo doméstico y una cantidad de hilado semanal fija, con los borbones se sumó la constante demanda de algodón. Esto último, en parte, porque el algodón se usaba como moneda de cambio. La ausencia o evasión a las demandas económicas exigida a las mujeres fueron castigadas con azotes y carga de agua. Paralelamente, las manifestaciones de insubordinación femenina, tales como las "desvergüenzas y réplicas" referenciadas por Guiraobi en el caso de María, podían conllevar encierros.

El segundo caso está centrado en el expediente judicial originado tras la acusación de un cabo de infantería portugués, residente en Buenos Aires, por la salida de su mujer de la ciudad, sin su autorización. El 4 de febrero de 1797, José Quirino de Carvalho denunció ante el "Excelentísimo Señor Virrey" que "su mujer legítima llamada María Rafaela de la Torre ha emprendió viaje fugitivo para la ciudad de Córdoba o Mendoza en una tropa en compañía de un mendocino" (Tribunales, 1797, f.1), y exigió:

mandar la correspondiente orden a las respectivas guardias de su tránsito para que se aprenda y se traiga ante la reconocida integridad de VE y presente la correspondiente licencia que debió obtener de esta superioridad o de su legítimo marido y no justificando la una como la otra se ponga en la Residencia donde con su trabajo personal se mantenga o habiendo yo de mantener haya de estar su trabajo personal anexo a mi voluntad pues así parece justicia (Tribunales, 1797, f.1).

Pocos días después, Quirino obtuvo autorización del virrey para que los comandantes y justicias de tránsito intercepten y detengan a Rafaela. La legislación lo amparaba, ya que con solo denunciar que su "mujer legítima" se había ido de su casa, sin aviso, podía ordenar que la trajeran de regreso (Kluger, 2003). Esto conllevaba un delito, el de fuga, por el cual se la podía detener y encerrar. A los fines de la detención describió las "señas de la contenida". Dijo ser una "mujer alta y achinada de pelo largo y negro", de 35 años. Tener "el rostro empañado" y en la frente "dos cicatrices como una cruz" y en "un codo una lastimadura acicatrizada" (Tribunales, 1797, f.3). El 11 de febrero, tras un informe realizado por el capitán de dragones, los cabos militares de la jurisdicción de Córdoba interceptaron la carreta en la que viajaba Rafaela, rumbo a Mendoza. Rafaela había salido de Buenos Aires el 27 de enero, junto a su madre, Mercedes Soria, viuda y natural de la ciudad de Córdoba, quien llevaba consigo dos nietos pequeños. Lxs acompañaban, en otra carreta del mismo tropero, su hermana María Bicenta y su hermano José. Rafaela y su madre se habían trasladado en la carreta de Eduardo Sosa, un próspero comerciante de la ciudad de Tucumán, quien llevaba, a su vez, "negros y géneros" adquiridos en el puerto de Buenos Aires para venderlos en las jurisdicciones del norte. A Quirino le bastó solo su nombre como la suposición de una "ilícita correspondencia” entre el tropero Sosa y Rafaela para afirmar que la llevaba "fugitiva" e iniciar de forma paralela un litigio contra aquel. Para ello, solicitó y logró ser declarado "pobre” por la Real Audiencia de Buenos Aires, a los fines de quedar exento de los costos judiciales (Tribunales, 1797, f. 2, 12 y 59).

Tras ser detenidas, Rafaela y su madre fueron enviadas a la ciudad de Mendoza y encerradas en la Real Cárcel por orden del Comandante de Armas, José Francisco Amigorena. El proceso se realizó "a costa del mismo Sosa" por haber conducido "clandestinamente a una mujer casada”. El 15 de marzo, Mercedes Soria presentó un escrito desde la cárcel, dirigido al virrey, donde solicitó se "sirva mandar salga yo de aquí", estando "en tan lamentable lugar llena de confusión" en "mis años", "con tanta familia" y "tan enferma”. Luego de obtener su libertad, "suplicó humildemente que "en virtud de estar tan próximo el viaje a esta de Buenos Aires" y por no ser "causa de que no puede resultar pena corporal" para Rafaela "se le soltare de la prisión", en la que se hallaba. A tal fin, Mercedes y el trapero Sosa pagaron la fianza, con sus bienes mancomunados. Tiempo después, Sosa en su defensa diría, entre otras cuestiones, que había sido no solo injustamente culpado, sino obligado a pagar la fianza y a costear el viaje de regreso. Una vez en la capital virreinal, Rafaela fue transitoriamente "deportada en la casa del agente" para luego quedar recluida en "la misma calidad en la casa de la Residencia” del Colegio de San Miguel (Tribunales, 1797, f. 2v, 4, 5, 8 v y 17). 
La disputa, precedida a su vez por otros pleitos entre las partes, no concluyó con este hecho ya que Quirino se resistió a pagar su manutención durante la reclusión en la Residencia. Por el contrario, Quirino ofreció

alimentarla bajo la precisa condición de que el sujeto destinado al cuidado de las mujeres que allí se reclusan me entregue cuanto lo referido mi mujer ganare por medio del trabajo al que se le dedique (Tribunales, 1797, f. 18).

Desde la Residencia, Rafaela promovió la intervención del "oidor y alcalde de corte de la Real Audiencia y juez de provincia” para que Quirino "contribuyese con mesada" y pagase la manutención durante su reclusión en el Colegio de San Miguel (Tribunales, 1797, f. 47). Como su madre había fallecido, a pocos días del viaje de regreso de Mendoza, Rafaela no pudo contar con la posibilidad de ser entregada a aquella, en custodia, como preveían las ordenanzas en estos casos. Por su parte, Quirino rechazó en reiteradas oportunidades pagar los alimentos de Rafaela en su reclusión y fue por ello "encarcelado en la Ranchería" (Tribunales, 1798, f. 60). Desde allí se negó, una y otra vez, a solventar a Rafaela y a levantar el litigio contra Sosa. A los fines de denunciar o defenderse, los actores recurrieron a diferentes autoridades. Cuando se solicitó la detención de Rafaela como así también cuando Mercedes pidió su excarcelación, se recurrió al virrey. Por su parte, cuando Rafaela solicitó su expósito de la Residencia como cuando reclamó su manutención buscó la intervención de la Real Audiencia Pretorial de Buenos Aires, que actuaba con independencia del Virrey, como de los juzgados ordinarios, en poder de los cabildos. Finalmente, Sosa presentó su defensa, a través de su procurador, ante los alcaldes de primer y segundo voto de Buenos Aires.

En el contexto colonial, la fuga del hogar conyugal estaba penada con la reclusión en casas especialmente destinadas para las mujeres. En las misiones guaraníes, por su parte, tanto los delitos morales, como eran los llamados "amancebamientos", así como el incumplimiento de las cargas comunales también conllevaron penas corporales y encierros. Las acciones descriptas redundaron en delitos en virtud de ciertas configuraciones de poder, cruzadas tanto por obligaciones de género como por demandas impuestas a la población de las reducciones. Por su parte, las fugas del hogar conyugal como de los pueblos, que se incrementaron en el contexto reduccional pos-jesuita como respuesta a las condiciones de vida, simbolizaron el desmembramiento social y la pérdida de privilegios patriarcales y coloniales. Las huidas, concebidas como una pérdida de poder, buscaron ser corregidas. Los castigos corporales fueron una de las principales respuestas políticas y jurídicas a la pérdida de control sobre los sujetos sociales. Al respecto, cabe preguntarse: ¿Qué matrices de dominio aunaban a María Irapayu y a Rafaela? ¿Qué representaciones sobre el cuerpo femenino operaron en la legitimación de los castigos físicos? ¿Qué implicaba castigar el cuerpo en el contexto colonial? A continuación, describiremos cómo los castigos físicos cristalizaron no solo concepciones culturales específicas sobre el cuerpo, en las que se condensaron sistemas jurídico-políticos, tradiciones religiosas, valores y esquemas morales disciplinantes, sino también estructuras de género desiguales.

\section{El CASTIGO CORPORAL: ORDEN POLÍTICO, CONCEPCIONES RELIGIOSAS Y CONFIGURACIONES DE GÉNERO}

El castigo del cuerpo condensó, históricamente, objetivos políticos y esquemas patriarcales y se alimentó de un heterogéneo corpus de escritos sobre teología moral, gobierno y derecho penal dentro de la monarquía católica. En el despliegue de un sistema punitivo se aunaron las potestades políticas y eclesiásticas, a los fines de sostener una unidad social y un orden jerárquico del mundo. Una antigua simbología del cuerpo humano como microcosmos referencial del cuerpo político y religioso fue retomada para reforzar la imagen monárquica (Le Goff y Truong, 2005 y Vigarello, 2005b). Además, ciertas concepciones cristianas consolidaron dualidades vinculadas al control y al dominio del cuerpo de fieles y súbditos. Entre ellas, las dualidades occidentales cuerpo y espíritu, carne y alma, y el binomio hombre-mujer con sus vínculos y jerarquías específicas, históricamente diversas. Dentro de este universo conceptual, el cuerpo físico, cambiante, con sus pulsiones, secreciones, olores y transformaciones, expresaba la dimensión de lo corrupto, lo incontrolable, lo caótico, lo impuro, lo imperfecto. Mientras que el alma, en tanto esencia 
inmaterial e inmutable, representaba la nobleza eterna, el ideal a perseguir. Estos imaginarios tomaron un lugar central con la Contrarreforma católica, la cual se esmeró en convertir a la "carne en todos los males" y a desarrollar mecanismos para sancionar "las insinuaciones" de la misma (Foucault, 2016 [1976], p. 21). Con el catolicismo pos-tridentino, dogmático por excelencia, las prácticas punitivas, disciplinantes y los sacrificios del cuerpo se radicalizaron junto con las representaciones negativas del mismo. La confesión y la penitencia adquirieron un rol nodal para lo cual se puso especial hincapié en la elaboraron de Manuales de confesores (Delemeu, 1992). La práctica confesional actuó como medio de disciplinamiento social y sexual (Arcuri, 2018).

La perdurabilidad y reproducción de estas modalidades de observación de las conductas corporales, a lo largo del tiempo, respondió, en buena medida, a su funcionalidad política, en la medida que alimentaban y legitimaban la permanencia de ciertos ordenes subyugantes, como era el sistema colonial. Por su parte, dada la fragmentación jurisdiccional, una de las principales herramientas de unificación y de obediencia, a una autoridad emanada de una distante e imaginaria figura monárquica, fue el miedo, encarnado en las consecuencias sociales, jurídicas y físicas que las desobediencias de casta, género y sector social podían conllevar. A este miedo se sumó el temor a dios, gracias a prácticas, preceptos y rituales religiosos que apuntalaron al control de las manifestaciones de los cuerpos, discriminados por su lugar social. En ese sentido, a los fines de la representación de un cuerpo político, inherente al sistema colonial, se defendieron preceptos de pureza y castidad. En consonancia, se instituyó la idea de que había cuerpos más puros y perfectos que otros y un modelo segregacionista necesario que sostener. De esta forma, se erigieron reglas de interacción social, selectivas, para mantener las especificidades de un grupo y la hegemonía de "élites blancas" sobre una mayoría indígena. La dimensión socio-cultural de lo corporal constituyó, finalmente, la principal vía de construcción de alteridad y subalteridad. Las categorías y denominaciones genéricas, tales como indios/ as, mestizos/as, mulatos/as, esclavos/as, mujeres, casi todas ellas nombradas María, se impusieron sobre los aspectos individuales y diferenciales de las personas. Las marcaciones sociales, impresas en los cuerpos, fueron selladas políticamente, a través de categorías jurídicas que implicaron, a su vez, derechos, obligaciones y penas diferenciales. $^{6}$

Los objetivos políticos descriptos se alimentaron de una red de concepciones sobre el control de las pulsiones del cuerpo que asentaron, a su vez, el rol disciplinador de élites civilizadas y occidentales (Elias, 1987). Los castigos conformaron prácticas purificadoras que buscaron reencauzar las corrupciones del cuerpo físico, del cuerpo social y del cuerpo político. Asimismo, constituyeron dispositivos de control social, de inmutabilidad y de reafirmación de las distancias sociales, raciales y de género. Los castigos corporales conllevaban encerrar, reducir, contener, separar, pero también dejar marcas, signos permanentes en el cuerpo. Los cuerpos marcados eran cuerpos controlados que ejemplificaban el poder y el sufrimiento que podía recaer sobre ellos si no obedecían las normas y códigos sociales. Las marcas aleccionaban y mantenían presente el lugar en la sociedad al mismo tiempo que justificaban el padecimiento de ciertos cuerpos, por la bajeza innata de las personas a las que representaban (Araya Espinoza, 2006). Esto se reproducía en las relaciones de género. En ese sentido, las mujeres, en especial en determinados ámbitos sociales y judiciales, debían "comportarse", lo que implicaba cuidar el tono de voz, los gestos y la vestimenta (Albornoz Vásquez y Argouse, 2009). Asimismo, en la estipulación de castigos particulares para las mujeres se expresaron las diferencias sociojurídicas entre varones y mujeres y las particulares concepciones de cuerpo y persona. Al respecto, la ley penal dentro de la monarquía hispana contempló, siguiendo las opiniones de los teólogos y los juristas, el concepto de "castigo moderado" que se expresó en la aplicación de menor cantidad de azotes, para las mujeres, en virtud de la mayor fragilidad de sus cuerpos y en tanto potenciales reproductoras. También, en tanto eran consideradas personas de racionalidad inferior, lo que conllevaba una posible puesta en duda de la conciencia de sus actos (Hespanha, 2001). 
El cuerpo de las mujeres se concebía como objeto potencial de control, castigo y corrección. La vigilancia de sus conductas se asentaba, en parte, sobre antiguas tradiciones de pensamiento, inscriptas en el derecho común y en la teología moral, que imaginaban a las mujeres como carnales en esencia, con una naturaleza ambigua que combinaba procreación, regeneración y potencial degeneración (Araya, 2004). No obstante, los vínculos entre impureza, contaminación y amenaza al orden social como la configuración de normas y moralidades, junto al despliegue de sanciones y castigos, no respondían únicamente a un entramado de lógicas occidentales cristianas, tal como extensamente lo expuso Mary Douglas (1973). Al respecto, en su obra "Pureza y peligro", la antropóloga dio cuenta, a través de diferentes casos extraídos de sociedades africanas, que la contaminación podía vincularse tanto a los cuerpos masculinos como femeninos, siendo mayores las situaciones en las que se atribuían fuerzas peligrosas y debilitantes a los contactos con las mujeres. Asimismo, como contrapunto con el catolicismo pos-tridentino, Caroline Walker Bynum (1990) hizo hincapié en que en la Baja Edad Media las experiencias corporales conformaban una vía de "acceso a lo sagrado" y que en los relatos milagrosos descriptos por mujeres "se desdibujaban las líneas que separaban lo espiritual y lo corporal, incluyendo el plano psicológico y sexual” (Walker Bynum, 1990, pp. 167 y 171). En contraste, la cultura católica de la contrarreforma desplegó una intensa pedagogía de la sexualidad, asociada al sacramento del matrimonio, a la selección de los cónyuges y al control de la descendencia. Se ejerció, además, una particular vigilancia de las conductas de las mujeres por su "condición de procreadoras" y por su representación como mediadores y reproductoras de determinados modelos y jerarquías sociales.

En la América colonial, la potencial impureza de los cuerpos femeninos en relación a su graduación socioracial conformó un pensamiento hegemónico que se expresó en las políticas de gobierno, en el sistema punitivo y en la vida cotidiana. En esa línea, mujeres esclavas o indígenas podían recibir la pena del azote cuando incumplían normas morales o serviles. Mujeres mestizas o mulatas libres podían, a su vez, ser amenazadas en las calles con golpizas en público por otras mujeres de condición social más elevada, cuando estas últimas consideraban que aquellas habían incurrido en comportamientos sociales inadecuados o cuando concebían haber sido injuriadas. De esta forma, en el mantenimiento de un orden social y moral actuaban otras mujeres que "colaboran en la vigilancia de las demás" (Albornoz Vásquez y Arguse, 2009, p.6). El valor de los cuerpos no solo se inscribía en determinadas relaciones de poder que aludían a dualidades de género sino a esquemas socio-raciales desde donde se estipulaban obligaciones y comportamientos aceptables. Sobre los mestizos y, en especial sobre las mujeres mestizas, recaían la sospecha y la mancha de la bastardía y la ilegitimidad (Bernand, 2001 y López Beltrán, 2008).

Asimismo, bajo patrones de dominio masculino, expresados en los deberes y obligaciones conyugales, las mujeres debían aceptar las decisiones que el marido pudiese tomar en relación al lugar de residencia, las obligaciones domésticas o los comportamientos y vínculos sociales. En la cultura hispana y americana de fines del siglo XVIII, se concebía como legítimo el castigo físico "discreto y moderado" con el objeto de "corregir y enmendar" en el "ejercicio de la autoridad marital”, cuando la esposa incumplía normas de sujeción o cuando dañaba su honor o el de la familia (Kluger, 2003, p. 157). Y “aunque el derecho castellano no concedió explícitamente a los hombres la facultad de golpear a sus esposas” la doctrina jurídica y canónica lo consideró aceptable (Kluger, 2004, p. 13). Por su parte, las "golpizas" estaban no solo justificadas sino recomendadas por los exponentes de la teología moral y pastoral. En los confesionarios existía la convicción de que los "castigos impuestos por los hombres eran tolerados por las mujeres porque tenían un carácter correctivo y, en consecuencia, edificante" (Boyer, 1991, p 289). Sin embargo, existían límites -aunque ambiguos- en relación a "lo permisible y adecuado" que dieron origen a extensos litigios por "malos tratos" (Stern, 1999, p. 23). La principal herramienta de las mujeres fue ahondar, con apoyo de ciertos letrados y familiares, en los intersticios de las obligaciones matrimoniales para resistir o contrapesar la violencia marital (Boyer, 1991; Kluger, 2003 y Stern, 1999).

La complejidad y ambigüedad aludidas, en relación con la potestad implícita dada a los maridos para castigar y contener a las mujeres, dentro de la unión conyugal, y con la práctica judicial instituida para 
defenderlas y protegerlas en caso de que aquellas denunciaran que estos habían traspaso el límite, se manifestaron en el litigio descripto entre Rafaela de la Torre y José Quirino. Con anterioridad al viaje, por el cual se generó la acusación de fuga por parte de Quirino, Rafaela había sido recluida en la Residencia de San Miguel. Esta primera reclusión, que se extendió por siete meses, había sido también promovida por su marido. Sin embargo, estando encerrada Manuela apeló a "los juzgados ordinarios como al tribunal de la Real Audiencia" para lograr su expósito. Finalmente, fue "despremiada” por la Real Audiencia y salió de la Residencia. Este proceso se dio en consonancia con el "decreto" obtenido por su madre con el objetivo de que Rafaela fuese "entregada a su cargo y cuidado". Asimismo, la Real Audiencia ordenó, en palabras de Rafaela, "al alcalde de barrio en que vivíamos que cuidase que Quirino Carvalho no anduviese por las inmediaciones de mi casa por temerse fundamentalmente una tropelía en mi persona" (Tribunales, 1796 y 1797, f. 42,43 y 44). El temor de un encuentro con Rafaela había sido expresado por su madre, desde la cárcel de Mendoza, en una extensa carta dirigida al virrey. En esa instancia describió a Quirino como un "hombre perverso" que

perdiendo su marido sus propias facultades llegó a extremo que mandó la real justicia una orden que fuese leída al alcalde de barrio mandando hubiese gran cuidado y ni aun le permitiera por aquella calle que se metiera en malo ni en bueno con mi hija (Tribunales, 1797, foja 4).

Finalmente, el tropero Sosa, a través de su procurador, también se refirió a Quirino en esos términos. En esa instancia, buscó desvincularse de la imputación de trasladar a una mujer casada y argumentó que "al tiempo de la marcha se hallaban separados por autoridad judicial". A su vez, hizo hincapié en que Mercedes Soria con la custodia de su hija había pretendido que no quedase "en brazos de un marido para que cuantos medios le dictaba la cavilosidad que solo aspiraba a labrar los eslabones para la cadena de su ruina" (Tribunales, 1798, foja 38). De manera elíptica, en los tres testimonios se aludió al peligro que Quirino representaba para Rafaela. Una amenaza a la integridad de su persona que no terminó de definirse en palabras, en el expediente, ni en un divorcio, pero que había conllevado, en la práctica, la separación de los cuerpos como medida judicial preventiva.

Los maltratos o las amenazas que los maridos podían llegar a desplegar sobre sus esposas, en ciertos sectores sociales de las ciudades hispano-americanas, se correspondían, en cierto sentido, a los que las mujeres indígenas podían padecer, en relación a su condición jurídica colonial, por parte de los administradores hispano-indígenas. En el caso de las mujeres de los pueblos guaraníes, la violencia ejercida en el espacio doméstico cobraba otra lógica al encontrarse, tanto hombres como mujeres, bajo la autoridad de jefes de familias extensas como de una administración hispano-indígena. Por su parte, las mujeres estaban supeditadas a históricas configuraciones de género sedimentadas sobre enraizadas desigualdades. Cabe solo mencionar la práctica prehispánica del "robo de mujeres", entre comunidades vecinas o enemigas, la "entrega de mujeres" como alianza política y el sostén cotidiano de las aldeas a través del brazo agrícola de las mismas (Susnik, 1966). A esto se sumó la práctica de la poligamia y la "circulación de mujeres" a los fines políticos, sexuales, serviles y reproductivos. Por su parte, el matrimonio cristiano, impuesto por los jesuitas, si bien puso ciertos límites a lo poligamia, por lo menos en su visibilidad, no anuló los privilegios de los hombres en general y de los caciques en particular sobre el trabajo de las mujeres.

La coacción laboral fue impuesta, bajo la administración de los jesuitas, por medio de los castigos físicos. Por su parte, la tarea de hilado dada a las mujeres generó resistencia entre las mismas, lo cual fue seguido de castigos públicos que los padres ordenaban, ocasionalmente, a todas las mujeres de un pueblo. El uso de los azotes en estos casos fue motivo de desavenencias al interior de la Orden (Quarleri, 2018). Esto generó un escenario de ambigüedad jurídica que se mantuvo tiempo después de la extradición de los jesuitas. En ese contexto y sumado a disputas de poder, María Irapuyu fue escuchada por el teniente de gobernador, el español Lasarte y Esquivel, quien abrió un expediente con presentación de testigos para demostrar que el castigo corporal no solo se había ejecutado de forma irregular, sino que expresaba un abuso de poder por parte del corregidor guaraní. Al respecto, María había denunciado que, luego de ser castigada "por Ignacia en las nalgas 
sobre lienzo con seis azotes", siendo que debería hacerse sobre su ropa, el ayudante Juliano Parabera le había impartido "con dureza en los hombros igual número de azotes, condenándosela después a tarea diaria por el dicho corregidor Miguel Guiraobi” (Provisión, 1788, f. 2). Pero también dio a entender, por la presencia de su marido en esa instancia de denuncia, que el reclamo solo podía hacerlo a través del mismo como así también que se encontraba demandada doblemente por su marido y por la administración hispana. Alegó, entonces, que su ausencia en la cosecha comunal fue injustamente castigada, sin embargo, no se condenó el castigo físico como sistema punitivo. Solo se cuestionó la forma en que se castigó el cuerpo de las mujeres.

Las penas corporales, como eran los encierros y azotes, aplicadas frente a la fuga del hogar conyugal como a la ausencia de la cosecha, siendo una tarea asignada dentro de un conjunto de obligaciones serviles de género, aunaron a dos mujeres insertas en entramados socio-jurídicos distintos. Sin embargo, la pena del azote, que dejaba marcas en el cuerpo y que solía devenir en enfermedades, abortos e incluso en la propia muerte, conformó el principal medio punitivo aplicado sobre la población indígena. Esto, en virtud de una valoración jerárquica de los sujetos en función de sus orígenes y de una clasificación estratificada de sus cuerpos. Asimismo, los azotes dados públicamente a las mujeres de los pueblos contenían un fin persuasivo y correctivo. En el caso de las mujeres españolas esta dimensión disciplinante era ejercida por los maridos dentro del ámbito doméstico, pero en tanto intermediarios de sistemas sociales que trascendían los vínculos conyugales. En ese sentido, la moral occidental y cristiana, que acompañó a la colonización, buscó unificar las conductas de las mujeres americanas de todas las condiciones sociales y jurídicas. Ejemplo de ello, como se verá, fue la creación de casas de recogidas tanto en las ciudades hispanas de América como en los pueblos misioneros.

\section{ENCERRAR Y CONTENER EL CUERPO FEMENINO: LAS CASAS DE RECOGIDAS}

Las casas de recogidas se crearon, hacia fines del siglo XVI, en España, en un contexto en que se pretendió controlar la circulación y presencia en las calles de "gente de mal vivir", vinculada a la "mendicidad", la "delincuencia” y la "prostitución femenina” (Pérez Baltasar, 1985, p. 13). La respuesta política fue la cárcel. Con el fin de sumar una dimensión correctiva a la punitiva, en materia de moralidad y disciplina femenina, se establecieron los recogimientos o casas de recogidas para mujeres que conllevaban un control sobre el uso de sus cuerpos y una reducción de sus movimientos fuera de los espacios contemplados para ellas. El encierro femenino, reforzado tras el Concilio de Trento, buscaba "sedentarizar" a mujeres consideradas transgresoras o díscolas creando, a su vez, "una esfera de protección” social (Onetto Pavez, 2009, p. 165). Estos espacios también recluían, aunquede forma separada, a huérfanas, viudas y mujeres sin medios de subsistencia. Las casas de recogidas fueron, a su vez, concebidas para depositar temporalmente a mujeres bajo un proceso de anulación marital, a mujeres culpadas por bigamia o a las llamadas "amásias" o concubinas. Actuaban como "prisión privada y pública para muchas mujeres acusadas de infidelidad conyugal, pecados públicos y rebeldía familiar" (Palma, 2009, p. 3). El recogimiento estaba, a su vez, asociado a la figura del "depósito" en la medida en que las mujeres eran jurídicamente asimiladas a un menor de edad, necesitadas de tutela y protección masculina (Ghirardi y Vassallo, 2010). El depósito de origen medieval solo fue cuestionado con las reformas liberales del siglo XIX (García Peña, 2006).

El recogimiento, asociado a la figura del depósito, podía llevarse a cabo en domicilios particulares, conventos, beateríos, hospitales para mujeres, espacios previamente asignados a huérfanas o casas ideadas para recogidas. En ese sentido, si bien en los virreinatos americanos se difundió tempranamente la política de recogimiento, la institución del depósito femenino no siempre se implementó en casas especialmente destinadas para ello por falta de recursos o aval institucional. Este fue el caso de Buenos Aires, en donde desde fines del siglo XVII se estipuló la idea de formar casas de protección para mujeres huérfanas, viudas o "perturbadoras" de la moral pública. Por entonces, existía la cárcel pública, separada de la de hombres, donde se encerraba a mujeres declaradas culpables de robos, crímenes o delitos morales, bajo condiciones edilicias, 
estado de hacinamiento e higiene deplorables. Durante mucho tiempo, los depósitos femeninos se llevaron a cabo, en Buenos Aires, en casas de personas particulares que contaban con una reputación pública honorable. A las mujeres de la élite, en particular, permanecer recogidas les ofrecía un resguardo para preservar el honor y la posición social frente a situaciones que podían incomodar a sus familias. Además, conllevaba un resguardo para las mujeres que hacían denuncias por maltrato. Cuando el pedido de recogimiento lo hacía un marido o familiar se le solicitaba que contribuyera con su alimento (Kluger, 2003). También se alojaba allí a viudas o solteras que pagaban su alojamiento y alimentación y a mujeres indígenas cautivas en las fronteras luego de expediciones de guerra (Mallo, 2004y Ratto, 2010). Tras la expulsión de los jesuitas, en 1767, se destinó parte del Colegio de San Miguel para albergar a recogidas. Específicamente, se usó para ello el espacio donde los jesuitas realizaban los "ejercicios espirituales" (Pérez Baltasar, 1985). Allí, debían llevar una vida de disciplina y oración y realizar labores e hilados para su manutención.

Un espacio similar fue concebido por la Compañía de Jesús para el complejo misionero del Paraguay. Desde principios del siglo XVIII, las autoridades de la Orden insistieron en que los padres a cargo de cada pueblo destinaran un lugar cerrado para el recogimiento de viudas, solteras y huérfanas. Esta medida fue reiterada por los provinciales jesuitas quienes, como intermediarios entre las políticas generales de la Orden y las prácticas misioneras, insistieron extensamente en la consigna institucional de crear y sostener estos espacios. El objetivo inicial fue la contención de mujeres solteras hasta su inserción en la sociedad por medio del casamiento, así como la "buena crianza" a los fines de "evitar ofensas a Dios" (Memoriales [1609-1767], 2015, p. 124). Sin embargo, dichas casas, nombradas alternativamente con los términos "cotiguazú", "tupaciro" o "casa de la virgen”, fueron sumando nuevas funciones, ya que también se recluyó en ellas a mujeres capturadas en entradas o campañas contra "indios infieles", emprendidas por los guaraníes con autorización de los jesuitas (Imolesi, 2011). Asimismo, la reclusión en estas casas buscó dar respuesta a la situación demográfica dispar, entre hombres y mujeres. La cantidad de mujeres "solteras", "sueltas" o "viudas", consignadas en los padrones, superaba ampliamente a la de los varones en la misma condición categorial. La diferencia numérica en los padrones podía explicarse por la muerte de sus esposos, en expediciones diversas, como por sus fugas y huidas de los pueblos, las cuales solían ser más elevadas que las de las mujeres. También por la poligamia masculina que, aunque en el contexto colonial se ocultó, siguió asociando a un hombre de prestigio con varias mujeres (Deckmann Fleck, 2006). La costumbre de recluir, allí, a toda mujer que no se encontrase bajo la potestad de un hombre llevó a la propia Compañía a ordenar que "no se obligue al recogimiento en dichas casas a las casadas que viven sin notas, ausentes sus maridos, ni a las solteras que tienen padre o madre" (Ordenes, 1724, f. 239).

Las autoridades jesuitas, en especial los provinciales, consideraban que las mujeres que incurriesen en delitos de orden sexual eran las que debían castigarse con el encierro en las residencias (Imolesi, 2012, p. 270). No obstante, con el tiempo se evidenció que en las casas de recogidas se encerraba no solo a mujeres castigadas por contravenir normas propias de la moralidad cristiana. La utilización de las residencias como medio generalizado de castigo femenino fue cuestionada por los provinciales de la orden. En ocasiones, estos sentenciaron que "el cotiguazú no es cárcel, sino casa de recogidas" (Memorial, 1740, f. 287). No obstante, más allá de la política oficial de recogimiento para mujeres desprotegidas y de disciplinamiento para las mujeres de "mal vivir", el cotiguazú condensó, en la práctica, diversas funciones punitivas. Este espacio no fue aceptado con agrado por las mujeres recluidas. A lo largo de casi todo el siglo XVIII, los provinciales repararon en las deplorables condiciones en las que se encontraban encerradas. Al respecto, se ordenó, por ejemplo, que "para que las recogidas del cotiguazú lleven suavidad y gusto el encerramiento se procurará acabar con la casa nueva que para ellas se ha comenzado" (Memoriales [1609-1767], 2015, p. 122). Con la expulsión de los jesuitas, el "cotiguazú" continuó cumpliendo, pese a todas las contrariedades, la función de cárcel de mujeres. Esto último, bajo nuevas circunstancias de convivencia hispano-indígena y disputas de poder.

En el contexto de la denuncia realizada por María Irapayu se elaboró un interrogatorio a diferentes testigos varones donde se preguntó, entre otras cuestiones, si el corregidor imputado también había ordenado 
encerrar en el "tupaciro" con un par de "grillos a Sinforosa Mbacarayu estando preñada por solo haber tenido noticia que esta china vivía mal con Casimiro Mbayucuru” o si consta que había puesto "en el tupaciro una mujer que se tenía de Yapeyú estando preñada en meses mayores" y que la "tubo con un par de grillos amenazándola con azotes” por haberse fugado de aquel pueblo (Testimonios, 1788, f. 4). En respuesta, el corregidor defendió sus acciones ya que los castigos no solo constituían una práctica que estaba naturalizada como forma de gobierno, dentro de una sociedad cruzada por la violencia, sino que en el caso de las mujeres sus desplazamientos o elecciones podían asentar, si no eran aleccionadas, una subversión a un modelo de sujeción de antigua data. Al respecto, no solo las mujeres sino también los hombres guaraníes estaban encerrados en las reducciones. Unxs y otrxs buscaron huir de sus pueblos hacia las ciudades o mezclarse entre pueblos frente a las condiciones de vida apremiante. Sin embargo, las fugas de hombres alcanzaban números más elevados. Esto último, entre otras cosas, fue resultado de la política de contención femenina ejercida por medio del encierro en casas de recogidas.

Desde otra óptica, Rafaela debió transitar el encierro en dos oportunidades por pedido de su marido. Este había utilizado las herramientas militares, políticas y jurídicas existentes para apresarla y castigarla con la reclusión. En ese contexto, alegó ser su esposo legítimo. Sin embargo, se negó a responder a las obligaciones de manutención que conllevaba el depósito cuando era ordenado por el marido, lo cual constituía un derecho para las mujeres que eran encerradas por sus cónyuges. La salida de su mujer de la ciudad alimentó su venganza, ya que esto expresaba, en sus palabras "un grave crimen", un atentado contra su potestad, en tanto consideraba que su mujer era de su dominio absoluto (Tribunales, 1797, f. 10), bajo cualquier circunstancia. Las sospechas sobre una posible relación con otro hombre incrementaron su encono y desprecio. Sin embargo, el viaje no implicó una posible fuga de una mujer con otro hombre, tal como Quirino había querido demostrar, sino una respuesta frente a la precariedad económica en la que se encontraban tanto Rafaela como su madre.

$\mathrm{Al}$ respecto, Mercedes había asentado ante la justicia que por sus deudas económicas se habían trasladado a Mendoza "para buscar trabajo en la cosecha" y que su yerno se había presentado falsamente en la justica diciendo que su hija "venía fugitiva". Según su mirada, esta situación había implicado una injusta detención y una mancha del honor familiar por "la vergüenza" de haberse "visto repentinamente culpada". Y se preguntaba: "dónde están los fueros de ser mujer" y "dónde el amparo del Rey mi Señor para con las viudas que por causa de un hombre perverso como es constante a todos" se "malogra" su vida (Tribunales, 1797, $\mathrm{f}$. 3v y 4). Mercedes falleció poco después de su regreso a Buenos Aires y Rafaela quedó recluida en la residencia, según la información contenida en el expediente. Las casas de recogidas, asociadas a la figura del depósito, reprodujeron las contradicciones entre contener y castigar, entre inmovilizar y proteger. Contradicciones que se cristalizaron, a su vez, en el propio tratamiento jurídico de mujeres como Rafaela que sin contar con recursos económicos quedaron especialmente expuestas. Por su parte, si bien la justicia colonial avaló los encierros ordenados por esposos como forma de castigo, también dio lugar a sus reclamos dentro de estructuras que condenaban de antemano a las mujeres por llevar la marca imborrable del pecado en sus cuerpos.

\section{A MODO DE CIERRE}

Los entramados suscitados a partir de las denuncias de castigos corporales y encierros conformaron una vía, entre otras, para ahondar en las concepciones culturales específicas sobre el cuerpo femenino y en las políticas de dominio, tradiciones jurídicas y religiosas que atravesaron contextos políticos y marcos culturales. Mujeres españolas como mujeres indígenas, pese a su condición socio-jurídica diferencial, se encontraron atravesadas por la criminalización de sus movimientos, cuando estos quedaron fuera de la esfera de control de las esferas de dominio instituidas. El desplazamiento o el incumplimiento de pactos implícitos fueron condenados, en ambos casos, siguiendo los esquemas legítimos existentes para ello: depositar en un espacio para mujeres o infringir dolor corporal de acuerdo al valor dado a los mismos en un esquema social racializado. 
En ese sentido, mujeres como Rafaela no recibirían como María Irapayu azotes públicos como medio de disciplinamiento. Sin embargo, las severidades domésticas, económicas y jurídicas vividas también la habían marcado. Con diferentes grados de libertad y diferentes posibilidades de resistir a la violencia ambas quedaron subsumidas bajo una misma coacción moral de carácter occidental y cristiana, condensada en un espacio común de reclusión.

El castigo corporal conllevaba, por su parte, una dimensión particular en el caso de las mujeres, en tanto eran concebidas por la teología moral como carnales en esencia y en virtud de un entramado socioreligioso y político que apuntaba a controlar las pulsiones del cuerpo. En ese sentido, sobre las mujeres recaía una compleja simbología, conductas restrictivas, relaciones e interacciones prescriptas, así como múltiples pedagogías corporales. A lo que se sumaba un orden punitivo en el caso de la mujer esclava, pobre o indígena. ¿Qué implicó castigar entonces a las mujeres guaraníes de las reducciones por parte de un corregidor indígena hispanizado? Desde el punto de vista del corregidor, los castigos eran un medio esencial de administración de justicia y gobierno. Asimismo, un medio correctivo contra la insubordinación que con sus "replicas ante el cabildo”, María Irapayu había asentado. También expresó un medio de control sobre los varones, ya que marcar los cuerpos femeninos significó también marcar límites de acción política masculina ¿Que implicó criminalizar a Rafaela por haberse ido de Buenos Aires? ¿Por qué las salidas o huidas de espacios domésticos eran delitos? La fuga de una mujer del espacio doméstico representaba el resquebrajamiento del orden social y del orden patriarcal delegado en el esposo y supervisado por las autoridades judiciales. La detención de Rafaela, también, expresó la disputa entre poderes masculinos. En ese sentido, la sola presencia de otro hombre en la esfera de influencia de su mujer, que consideraba ser de su dominio, había llevado a Quirino a denunciar el viaje de Rafaela y a transformarla en una fugitiva de la ley, amalgamando ley judicial con ley patriarcal.

\section{FUENTES INÉDITAS}

\section{Archivo General de la Nación (AGN)}

- Declaración de Miguel Guiraobi, San Lorenzo, 13 de febrero de 1788. AGN, Sala IX, 17-8-4.

- Provisión del teniente de gobernador de este Departamento de San Miguel, Don Manuel de Lasarte y Esquivel, por la queja dada por el cacique Don Agustín Guairaye, San Nicolás de Bari, 18 de enero de 1788. AGN, Sala IX, 17-8-4.

- Testimonios levantados por el corregidor de San Miguel, Pascual Areguati, al Secretario de mujeres Juan Guayacu, al mayordomo Ignacio Chembo, al sargento Gabriel Ibaye y al sargento Carlos Tarupira, San Lorenzo, 22 de enero de 1788. AGN, Sala IX, 17-8-4.

- Tribunales. José Quirino de Carvalho sobre la fuga de su mujer María Rafaela de la Torre, Buenos Aires, 4 de febrero de 1797. AGN, Sala IX. Tribunales. Legajo 40-7-3.

- Visita a Santos Apóstoles con pedido de publicación de Bando en los parajes acostumbrados, explicado en idioma guaraní, Santos Apóstoles, 3 de septiembre de 1787. AGN, Sala IX, 39.5.1.

Biblioteca Nacional de Madrid (BNM)

- Memorial del Padre Provincial Antonio Machoní para el Padre Superior de estas Doctrinas del Paraná y Uruguay y sus consultores en la Visita del 29 de Junio de 1740. BNM, Libro de Órdenes, ms 6979.

- Órdenes del padre Provincial Luis de la Roca para las Doctrinas del Paraná y Uruguay en la visita del año 1724. BNM, Libro de Órdenes, ms 6979. 
Fuentes editadas

- Memoriales de la Provincia jesuítica del Paraguay, siglos XVII-XVIII (2015). Piana, Josefina y Pablo Cansanello (comp.). Córdoba: EDUCC.

- Recopilación de Leyes de los Reinos de Indias (1681). Mandados a imprimir y publicar por la majestad Católica del Rey Don Carlos II Nuestro Señor (Tomo II, Libro VII). Madrid: Iulian de Paredes.

\section{REFERENCIAS}

Albornoz Vásquez, M. E. y Argouse, A. (2009). Mencionar y tratar el cuerpo: indígenas, mujeres y categorías jurídicas. Violencias del orden hispano colonial, Virreinato del Perú, s. XVII-XVIII. Nuevo mundo-mundos nuevos. Recuperado de http://journals.openedition.org/nuevomundo/53163

Araya Espinoza, A. (2004). La pureza y la carne: el cuerpo de las mujeres en el imaginario político de la sociedad colonial. Revista de Historia Socialy de las Mentalidades, 8(1/2), 67-90.

Araya Espinosa, A. (2006). El castigo físico: el cuerpo como representación de la persona, un capítulo en la historia de la occidentalización de América, siglos XVI-XVIII. Historia, 39(2), 349-367.

Araya Espinosa, A. (2014). Azotar el cuerpo. Prácticas de dominio colonial e imaginarios. Del Reino de Chile a la República. En V. Undurraga y R. Gaune (Eds.). Formas de control y disciplinamiento. Chile, América y Europa, siglos XVI-XIX (pp. 194-209). Santiago de Chile: Uqbar editores.

Arcuri, A. (2018). Represión sexual y de género en la confesión: los manuales de confesores en la Edad Moderna (siglos XVI-XVII). Ex equo, 37, 81-93.

Bernand, C. (2001). Mestizos, mulatos y ladinos en Hispanoamérica: un enfoque antropológico de un proceso histórico. En M. León Portilla (Coord.), Motivos de la antropología americanista. Indagaciones en la diferencia (pp. 105-131). México: FCE.

Boyer, R. (1991). Las mujeres, la "mala vida” y la política del matrimonio. En A. Lavrin (Coord), Sexualidad y matrimonio en la América hispánica: siglos XVI-XVII (pp. 271-308). México: Grijalbo.

Caletti Garciadiego, B. (2015). Milicias y Guaraníes en Yapeyú. La defensa de la "Frontera del Uruguay" en los albores del siglo XIX. Prohistoria, 23, 47-70.

Deckmann Fleck, E. C. (2006). De mancebas auxiliares do demônio a devotas congregantes: mulheres e condutas em transformação (reduções jesuítico-guaranis, séc. XVII). Estudos feministas, 14(3), 617-634.

Delemeu, J. (1992). La confesión y el perdón. Las dificultades dela confesión, siglos XIII a XVIIII. Madrid: Alianza Editorial.

Douglas, M. (1973). Pureza y peligro. Un análisis de los conceptos de contaminación y tabú. Madrid: Siglo XXI.

Elias, N. (1987). El proceso de la civilización. Investigaciones sociogenéticas y psicogenéticas. México: FCE.

Farge, A. (2008). Efusión y tormento, el relato de los cuerpos: historia del pueblo en el siglo XVIII. Buenos Aires: Katz Editores.

Foucault, M. (2016 [1976]). Historia de la sexualidad (vol. 1). Buenos Aires: Siglo XXI.

García Peña, A. L. (2006). El fracaso del amor. Género e individualismo en el siglo XIX mexicano. México D.F.: El Colegio de México, Universidad Autónoma de México.

Ghirardi, M. y Vassallo, J. (2010). El encierro femenino como práctica. Notas para el ejemplo de Córdoba, Argentina, en el contexto de Iberoamérica en los siglos XVIII y XIX. Revista de historia social y de las mentalidades, 14(2), 73-101.

Hespanha, A. (2001). El estatuto jurídico de la mujer en el derecho común clásico. Revista jurídica, 4, 71-87.

Imolesi, M. E. (2011). El sistema misional en jaque: la reclusión femenina en las educciones jesuíticas de guaraníes. Anos 90, 18(34), 139-158. 
Imolesi, M. E. (2012). Teoría y práctica de la cristianización del matrimonio en Hispanoamérica colonial. (Tesis de doctorado). Facultad de Filosofía y Letras, Universidad de Buenos Aires, Buenos Aires, Argentina. Recuperado de http://ravignani.institutos.filo.uba.ar/publicacion/ltr-002-imolesi

Imolesi, M. E. (2017). Soluciones jesuitas en entornos misionales: la aplicación del probabilismo en la resolución de dudas en torno a los matrimonios en las reducciones guaraníes. Historia y grafía, 25(49), 57-84.

Johnson, L., Socolow, S. y Seibert, S. (1980). Población y espacio en el Buenos Aires del siglo XVIII. Desarrollo económico, 20(79), 329-349.

Kluger, V. (2003). Escenas de la vida conyugal. Los conflictos matrimoniales en la sociedad virreinal rioplatense. Buenos Aires: QUORUM, UMSA.

Kluger, V. (2004). El rol femenino a través de los litigios familiares en el Virreinato del Río de la Plata (siglos XVIII y XIX). Iberoamericana, 9(14), 7-27.

Le Goff, J. y Troung, N. (2005). Una historia del cuerpo en la Edad Media. Barcelona: Paidós.

López Beltrán, C. (2008). Sangre y temperamento: pureza y mestizajes en las sociedades de castas americanas. En F. Gorbach y C. López-Beltrán (Eds.), Saberes locales: ensayos sobre historia de la ciencia en América Latina (pp. 289-342). Michoacán: El Colegio de Michoacán.

Maeder, E. (1992). Misiones del Paraguay. Conflicto y disolución de la sociedad guaraní. Madrid: Mapfre.

Mallo, S. (1990). La mujer rioplatense a finales del siglo XVIII. Ideales y realidad. Anuario del IEHS, 5, 117-132.

Mallo, S. (2004). La sociedad rioplatense ante la justicia. La transición del siglo XVIII al XIX. La Plata: Publicaciones del Archivo Histórico de la Provincia de Buenos Aires.

Moraes, M. I. (2007). Crecimiento del Litoral rioplatense colonial y decadencia de la economía misionera: un análisis desde la ganadería. Investigaciones de historia económica, 9, 11-44.

Onetto Pavez, M. (2009). De ideales y transgresiones en medio de una precariedad: la Casa de recogidas de Santiago de Chile, siglos XVII-XVIII. Revista de historia social y de las mentalidades, 13(1), 159-200.

Palma, M. de (2009). Recluidas y marginadas. El recogimiento de mujeres en el Buenos Aires colonial. (Tesis de licenciatura). Facultad de Filosofía y Letras, Universidad de Buenos Aires, Buenos Aires. Recuperado de http://repositorio.filo.uba.ar/bitstream/handle/filodigital/1173/uba_ffyl_t_2009_855613.pdf?sequence= 1\&isAllowed=y

Peréz Baltasar, M. D. (1985). Origen de los recogimientos de mujeres. Cuadernos de historia moderna y contemporánea, 6, 13-23.

Quarleri, L. (2012). Políticas borbónicas en los “pueblos de indios guaraníes": estratificación, mestizaje e integración selectiva. Nuevo mundo-mundos nuevos. Recuperado de http://journals.openedition.org/nuevomundo/64459

Quarleri, L. (2018). Castigos físicos y control de los cuerpos. Mujeres guaraníes, trabajo y poder colonial. Temas americanistas, 40, 239-264.

Ratto, S. (2010) ¿Para qué quieren tener cautivas si no estamos en guerra? Las variadas formas del cautiverio interétnico en la campaña bonaerense (primera mitad del siglo XIX). Boletín del Instituto de Historia Argentina y Americana, 32, 41-66.

Ratto, S. (2015). Tierras misionales en el litoral rioplatense (1750- 1800). En G. Caetanoy y A. Ribero (Coords.), Tierras, reglamento y revolución. Reflexiones a doscientos años del reglamento artiguista de 1815 (pp. 383-405). Montevideo: Planeta.

Sarreal, J. (2014). The Guarani and their missions: a socioeconomic history. Los Angeles: Stanford University Press.

Stern, S. (1999). La historia secreta del género: mujeres, hombres y poder en México en las postrimerias del periodo colonial. México: FCE.

Susnik, B. (1966). El indio colonial del Paraguay (tomo II). Asunción: Museo Etnográfico “Andrés Barbero”.

Tomás y Valiente, F. (1969). El derecho penal de la monarquía absoluta: siglos XVI-XVII-XVII. Madrid: Tecnos.

Vassallo, J. (2006). Delincuentes y pecadoras en la Córdoba tardocolonial. Anuario de estudios americanos, 63(2), 97-116.

Vigarello, G. (dir.) (2005a). Historia del cuerpo. Del Renacimiento a la Ilustración (vol. 1). Madrid: Taurus. 
Vigarello, G. (2005b). El cuerpo del rey. En Historia del cuerpo. Del Renacimiento a la Ilustración (vol. 1, pp. 373-394). Madrid: Taurus.

Walker Bynum, C. (1990). El cuerpo femenino y la práctica religiosa en la Edad Media. En M. Feher; R. Naddaff y N. Tazi (Eds.). Fragmentos para una historia del cuerpo humano (pp. 163-225). Madrid: Taurus.

\section{Notas}

1 Esta investigación forma parte del Proyecto PICT 1409/17 "Cuerpos marcados, cuerpos productivos: clasificaciones, transformaciones y resistencias (Río de la Plata, siglos XVIII y XIX)”. Instituto de Altos Estudios Sociales, Universidad Nacional de San Martín.

2 Se emplean las categorías de mujeres "indígenas" y "españolas" por conformar clasificaciones fiscales, jurídicas, sociales y morales de la época que condicionaban obligaciones y derechos.

3 En el Archivo General de la Nación (Argentina) en la Serie Tribunales y Criminales de la Sala IX se pueden encontrar denuncias de "adulterio, bigamia, rapto, malos tratos, heridas, asesinato, violación y estupro" que conforman un invaluable reservorio para indagar las prácticas sociales y judiciales desde la perspectiva de género. Para la región guaraní, los extensos legajos de la serie Misiones (1768-1806) constituyen un corpus documental de gran valor para el estudio, aún pendiente, de las disputas políticas, la violencia estructural y el maltrato cotidiano ejercido sobre las mujeres guaraníes.

4 Los castigos corporales más comunes eran los presidios, los trabajos, las cárceles y los azotes. La cárcel era concebida, en la legislación penal, como una reclusión cautelar hasta la condena. Sin embargo, en la práctica se concibió en sí misma como una pena corporal. En el caso de los sectores sin recursos materiales la cárcel, los trabajos y los azotes constituyeron la principal forma de castigo en contraposición con las penas pecuarias.

5 El pueblo de San Lorenzo era uno de los seis pueblos ubicados en la ribera oriental del río Uruguay, actual Río Grande del sur (Brasil). Los otros veintitrés pueblos estaban localizados en la banda occidental del Uruguay y sobre el río Paraná, en las actuales fronteras de Brasil, Argentina, Paraguay y Uruguay.

6 En Las Leyes de Indias de dictaminó que "los delitos contra los indios sean castigados con mayor rigor, que contra los españoles" (Recopilación, 1681, p. 299). 